\title{
A20 zinc finger protein inhibits TNF-induced apoptosis and stress response early in the signaling cascades and independently of binding to TRAF2 or 14-3-3 proteins
}

\author{
U Lademann ${ }^{1}$, T Kallunki ${ }^{1}$ and M Jäättelä ${ }^{\star, 1}$ \\ ${ }^{1}$ Apoptosis Laboratory, Institute of Cancer Biology, Danish Cancer Society, \\ Strandboulevarden 49, DK-2100 Copenhagen, Denmark \\ * Corresponding author: M Jäättelä, Apoptosis Laboratory, Institute of Cancer \\ Biology, Danish Cancer Society, Strandboulevarden 49, DK-2100 \\ Copenhagen, Denmark. Tel: 45-35257318; Fax: 45-35257721; \\ E-mail: mhj@biobase.dk
}

Received 22.8.00; revised 23.10.00; accepted 30.10 .00 Edited by J Tschopp

\begin{abstract}
A20 zinc finger protein is a negative regulator of tumor necrosis factor (TNF)-induced signaling pathways leading to apoptosis, stress response and inflammation. A20 has been shown to bind to TNF-receptor-associated factor 2 (TRAF2) and 14-3-3 chaperone proteins. Our data indicate that the zinc finger domain of A2O is sufficient and that neither TRAF2 nor 14-3-3 binding is necessary for the inhibitory effects of A20. Mutations in the 14-3-3 binding site of A20 did, however, result in a partial cleavage of A20 protein suggesting that 14-3-3 chaperone proteins may stabilize A20. Furthermore, we show that A2O acts early in TNF-induced signaling cascades blocking both TNF-induced rapid activation of c-Jun Nterminal kinase and processing of the receptor-associated caspase-8. Taken together our data indicate that the zinc finger domain of A20 contains all necessary functional domains required for the inhibition of TNF signaling and that A20 may function at the level of the receptor signaling complex. Cell Death and Differentiation (2001) 8, 265-272.
\end{abstract}

Keywords: A20 zinc finger protein; apoptosis; caspase; JNK; $N F-\kappa B ; T N F$

Abbreviations: AP-1, activator protein 1; FADD, Fas-associated death domain protein; IL-1, interleukin-1; JNK, C-Jun N-terminal kinase; MTT, dimethylthiazol-diphenyltetrazolium; NF- $k$ B, nuclear factor kappa B; RIP, receptor associated protein; TBS, tris-buffered saline; TNF, tumor necrosis factor; TNF-R, tumor necrosis factor receptor; TRADD, tumor necrosis factor associated death domain protein; TRAF, tumor necrosis factor receptor-associated protein; wtA20, wild type A20

\section{Introduction}

Tumor necrosis factor (TNF) is a multifunctional cytokine that can elicit several biological responses including apoptosis, inflammation and stress response. ${ }^{1-3}$ The numerous biological effects of TNF are signaled via two distinct cell surface receptors, TNF-R1 and TNF-R2, the former being the major signaling receptor in most cells. Trimerization of TNF-R1 by TNF trimer leads to the trimerization of intracellular death domains of the receptor and their subsequent binding to other intracellular death domain containing proteins. The TNF-R1 death domain first binds to TNF-R1-associated death domain protein (TRADD), which serves as a platform for at least three adapter proteins activating three distinct signaling pathways. ${ }^{4,5}$ The apoptotic signal is initiated by binding of TRADD to the Fas-associated death domain protein (FADD). ${ }^{4}$ FADD in turn recruits a cysteine protease, caspase-8, to the receptor complex, where caspase-8 is activated possibly by proteolytic cleavage mediated by itself. ${ }^{6,7}$ In addition to FADD, TRADD also recruits a serine/ threonine kinase named receptor interacting protein (RIP) and TNF-R-associated factor 2 (TRAF2), both of which are implicated in the activation of nuclear factor kappa B (NF$\kappa \mathrm{B}$ ) and C-Jun $\mathrm{N}$-terminal kinases (JNK, also known as stress-activated protein kinases), RIP being crucial for the activation of NF- $\kappa$ B and TRAF2 for that of $\mathrm{JNK}^{4,8,9}$ the role of JNK pathway in apoptosis signaling is still controversial. Based on results obtained with inactivated upstream kinases as well as with a dominant negative mutant of a JNK substrate, c-Jun, the JNK pathway leading to the activation of activator protein 1 (AP-1) has been suggested to be essential for TNF- and stress-induced apoptosis. ${ }^{10,11}$ Other results argue, however, that TNF-induced activation of JNK is not linked to the apoptotic pathway. ${ }^{12,13}$ Interestingly, the most recent experiments employing JNK-1/JNK-2 double knockout mice suggest that the effect of these kinases on developmental apoptosis can be either enhancing or inhibiting depending on the cell type. ${ }^{14}$ Even though it is best known as the major activator of several pro-inflammatory genes, ${ }^{15}$ also NF- $\kappa$ B influences the apoptotic pathway with profound protective effects against TNF- and chemotherapy-induced cell death. ${ }^{16-18}$

A20 is a primary response gene that encodes an $80 \mathrm{kDa}$ protein, whose C-terminus consists of seven $\mathrm{Cys}_{2} / \mathrm{Cys}_{2}$ zinc fingers. $^{19,20}$ A20 effectively inhibits TNFand interleukin-1 $\beta$ (IL-1 $\beta$ )-induced apoptosis as well as activation of NF- $\kappa \mathrm{B}$ and $\mathrm{AP}-1$ transcription factors. ${ }^{21-25}$ As the expression of $A 20$ is upregulated by inflammatory cytokines TNF and IL-1 $\beta$, its ability to shut down signaling from their receptors may serve an important function in negative feedback regulation of inflammatory processes. Indeed, mice deficient for A20 die prematurely due to severe inflammation and cachexia and are hypersensitive to TNF. ${ }^{26}$ Furthermore, A20 expression in human tumors has been suggested to be linked to enhanced tumorigenesis via resistance to apoptosis. ${ }^{20,27}$ 
A20 binds to TRAF2 involved in TNF-induced activation of NF- $\kappa$ B and AP-1 and to TRAF6 implicated in the IL-1induced activation of these transcription factors. $4,24,28,29$ Yeast two-hybrid studies have also revealed binding of A20 zinc finger domain to 14-3-3 chaperone proteins, whose expression alters the distribution of $A 20$ in the cytosol from punctuate to diffuse pattern. ${ }^{30}$ Ubiquitously expressed 14-3-3 proteins bind to several other signaling molecules and may regulate their activities in a phosphorylation-dependent manner. ${ }^{31}$ For example, the binding of 14-3-3 to phosphorylated Bad or the Forkhead transcription factor inhibits their pro-apoptotic functions suggesting a role for 14-3-3 protein interactions in the regulation of apoptosis. ${ }^{32,33}$ Binding of neither TRAF2 nor 14-3-3 to $A 20$ is required for the A20-mediated inhibition of NF- $\kappa \mathrm{B}$ activation, ${ }^{34}$ but their role in the $\mathrm{A} 20$ associated regulation of apoptosis and stress response has not been studied.

We studied the mechanism of action of A20 by introducing A20 cDNA and its mutants lacking either most of the zinc finger domain, TRAF2-binding domain or 14-3-3 binding domain into MCF-7S1 breast cancer cells. These cells express undetectable levels of endogenous A20 and respond to TNF treatment by activation of NF$\kappa \mathrm{B}$ and AP-1 followed by apoptosis allowing us to compare the effects of $\mathrm{A} 20$ and its mutants on various TNF-induced signaling pathways. ${ }^{21,22}$ Our results show that A20 inhibits TNF-induced apoptosis already at the level of caspase-8 processing. Also the inhibition of TNFinduced stress response occurs early, as A20 inhibits the rapid activation of JNK responsible for the activation of AP-1. Furthermore, our data show that the C-terminal zinc finger domain of $\mathrm{A} 20$ is sufficient not only for the inhibition of NF- $\kappa \mathrm{B}$ activation but also for the inhibition of apoptosis and JNK activation, and that the binding of A20 to 14-3-3 proteins is not required for any of these functions of A20.

\section{Results}

\section{The zinc finger domain of A20 protein is sufficient to inhibit TNF-induced apoptosis}

To determine which domain of A20 protein is necessary for its inhibitory functions, we introduced cDNAs encoding for the wild type A20 (wtA20), N-terminus of A20 containing the TRAF2 binding domain, but lacking most of the zinc finger domain (A20-N), C-terminus of A20 containing the complete zinc finger domain, but lacking the TRAF2 binding domain $(A 20-C)$ and $A 20$ lacking the middle part of the (A20- $\triangle M)$ into MCF-7S1 cells. All cDNAs were cloned into pZEM-neo expression vector downstream of metallothionine promoter. The pooled populations of transfected MCF-7S1 cells (neo, wtA20, A20-N and A20-C) as well as successfully transfected single cell clones (neo-1, neo-2, wtA20-4, wtA20-8, A20-N-26, A20-N-31, A20-C-1 and A20-C-4) were cultured with or without $10 \mu \mathrm{M} \mathrm{CdCl}$ and analyzed for the expression of A20 protein. As shown in Figure 1, both pooled populations and single cell clones transfected with wtA20, A20-N or A20-C expressed detectable levels of transfected proteins of expected sizes even in the absence of $\mathrm{CdCl}_{2}$, indicating that the metallothionene promoter is leaky in MCF-7 cells. The expression levels could, however, be slightly increased by $\mathrm{CdCl}_{2}$ treatment. In spite of several attempts, we failed to express detectable levels of the A20- $\Delta \mathrm{M}$ mutant in MCF-7S1 cells.

As we have shown earlier with independent transfectants, ${ }^{22}$ single cell clones of MCF-7S1 cells constitutively overexpressing wtA20 were clearly protected from TNFinduced cell death (Figure 2A). To avoid misinterpretations of the data due to possible clonal variation among the single cell clones, we next tested whether pooled populations of transfectants could be used to study the effects of $A 20$ and its mutants on TNF signaling. As shown in Figure $2 \mathrm{~B}$, the pooled population of MCF-7S1 cells expressing wtA20 was significantly protected from cell
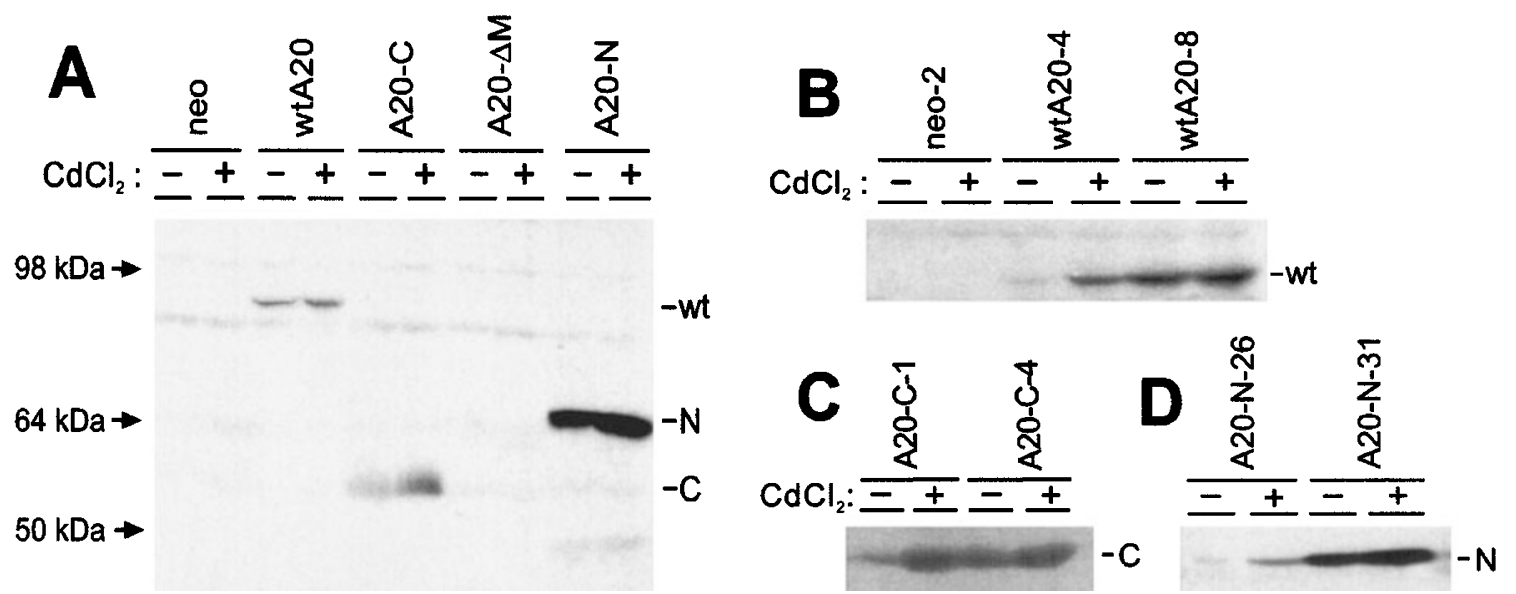

Figure 1 Expression of A20 protein and its mutants in MCF-7S1 cells. MCF-7S1 cells were transfected with empty pZEM-Neo vector (neo) or pZEM-Neo encoding wild type A20 (wtA20), N-terminal half of A20 (A20-N), C-terminal half of A20 (A20-C) and A20 lacking the middle part of protein (A20- $\Delta$ M). Shown are pooled populations $(\mathbf{A})$ and single cell clones (B-D). Cells were left untreated $(-)$ or treated $(+)$ with $10 \mu \mathrm{M} \mathrm{CdCl}_{2}$ for $6 \mathrm{~h}$ before preparations of cell lysates. Proteins from approximately $7.5 \times 10^{5}$ cells were analyzed using an anti-FLAG antibody (M2) and ECL Western blot analysis system. The migration of molecular weight markers is indicated on the left and that of wtA20 (wt), A20-N (N) and A20-C (C) on the right 


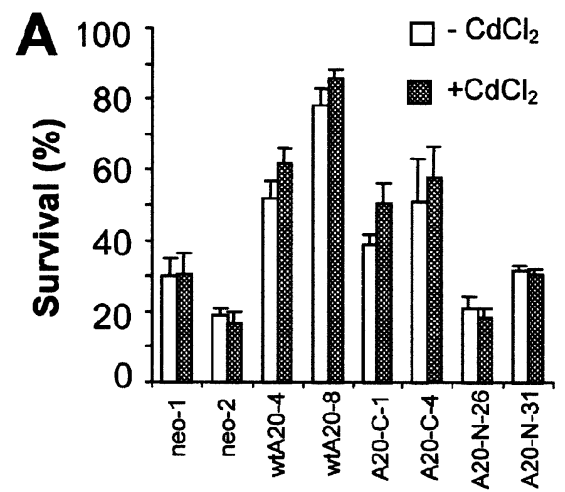

B
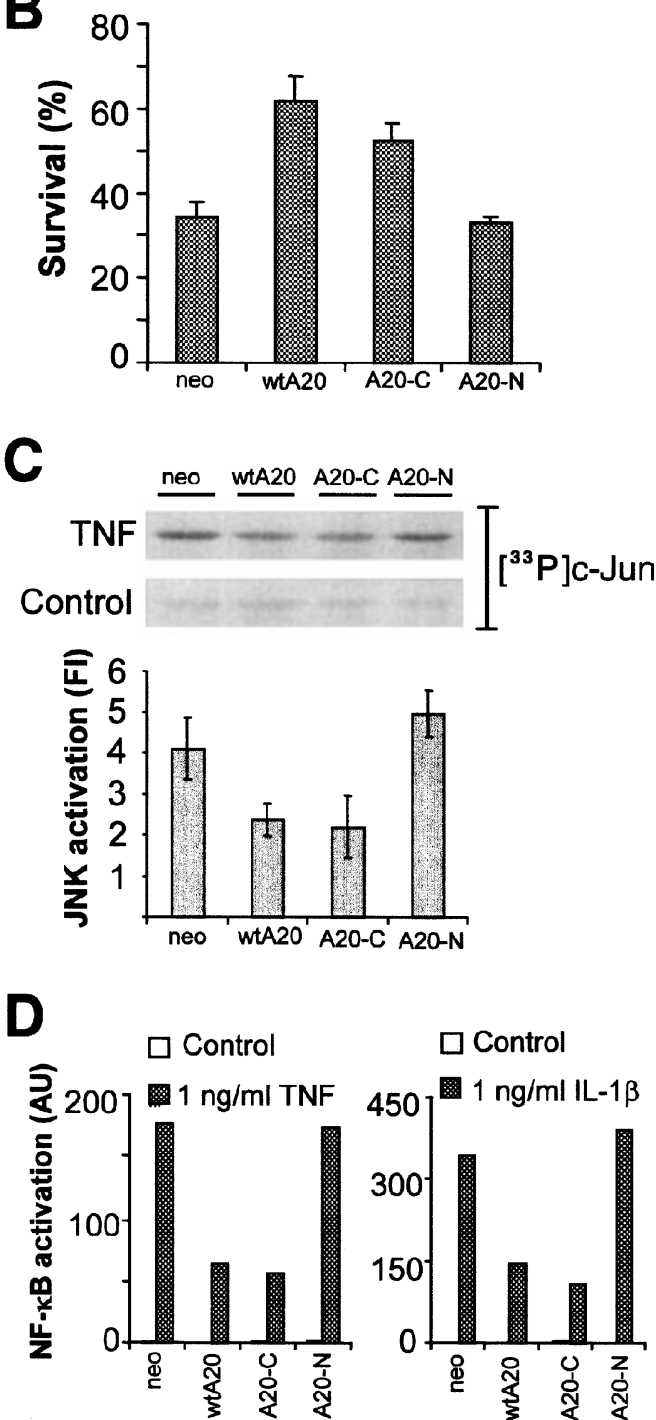

Figure 2 The zinc finger domain of $A 20$ is sufficient for A20-mediated inhibition of TNF-induced cell death $(\mathbf{A}, \mathbf{B})$, JNK activation $(\mathbf{C})$ and NF- $\kappa$ B activation (D). (A,B) Approximately 3500 cells/well were plated on 96-well plate and 1 day later $5 \mathrm{ng} / \mathrm{ml}$ of TNF was added. The percentage of surviving cells was analyzed by MTT assay after 72-h treatment. When indicated cells were treated with $10 \mu \mathrm{M} \mathrm{CdCl}_{2}$ for $6 \mathrm{~h}$ before the addition of TNF. The values represent means of three independent triplicate experiments + S.D. (C) Cells were left untreated (control) or treated with $10 \mathrm{ng} / \mathrm{ml}$ TNF for $30 \mathrm{~min}$ prior to harvesting and measuring the JNK activity using a solid-phase kinase assay. Phosphorylated GST-c-jun was quantitated by phosphorimager and the TNF- death induced by TNF $(P<0.01)$. Next we studied the TNF sensitivity of pooled populations and single cell clones expressing the mutant $\mathrm{A} 20$ proteins. In both cases the zinc finger domain of A20 (A20-C) protected MCF-7S1 cells from TNF-induced apoptosis $(P<0.05)$. Furthermore, the clear $\mathrm{CdCl}_{2}$-induced increase in $\mathrm{A} 20-\mathrm{C}$ expression seen in MCF-A20-C-1 cells (Figure 1C) was associated with increased protection from TNF $(P<0.05)$. Both pooled populations and single cell clones of MCF-7S1 cells expressing high levels of A20-N were as sensitive to TNF as vector-transfected control cells and their sensitivity was not affected by $\mathrm{CdCl}_{2}$ treatment (Figure 2).

\section{A20 inhibits JNK activation even in the absence of the TRAF2 binding domain}

We have earlier shown that A20 inhibits TNF-induced activation of AP-1. ${ }^{22}$ To study at which step of the signaling cascade this inhibition occurs, we studied the effect of A20 expression on TNF-induced activation of JNK by a solidphase kinase assay. Interestingly, wtA20 clearly inhibited this early event of the AP-1 activation pathway (Figure $2 \mathrm{C}$ ). TRAF2 is critical for the TNF-induced activation of JNK. ${ }^{8}$ Thus, it was interesting to study whether the reported binding of A20 to TRAF2 is necessary for the A20-mediated inhibition of JNK activation. ${ }^{24}$ Surprisingly, the A20-C lacking the TRAF2 binding domain inhibited TNF-induced JNK activation as effectively as wtA20, whereas A20-N containing the TRAF2 binding domain, but lacking the zinc finger domain was without an effect (Figure 2C). As reported earlier in other cell types, TNF- and IL-1 $\beta$-induced activation of $\mathrm{NF}-\kappa \mathrm{B}$-like transcription factors was also effectively inhibited by overexpression of wtA20 and the C-terminal zinc finger domain of $\mathrm{A} 20$, whereas the $\mathrm{N}$ terminal domain of A20 failed to show any inhibitory activity (Figure 2D). Taken together these data indicate that the $\mathrm{C}$ terminal zinc finger domain is sufficient to mediate all inhibitory activities of TNF and that the binding of TRAF2 is not necessary for the function of A20.

\section{Binding of 14-3-3 to A20 stabilizes A20 but is not necessary for the A20-mediated inhibition of TNF signaling}

14-3-3 chaperone proteins bind to the phosphoserine residue in the RSKpSDP sequence of A20 located between zinc fingers 3 and $4 .{ }^{34}$ To investigate the possible effects of this binding on the activity of A20 we mutated the A20 14-3-3 binding site by changing the crucial serine-565 to arginine (A20-S565R). A mutation of serine-565 has recently been shown to completely inhibit the binding of A20 to $14-3-3 .{ }^{34}$ As

induced JNK activity is expressed as fold induction (FI) as compared to contro cells. The values represent means of three independent experiments \pm S.D. (D) Cells were transiently transfected with p3K-INF-LUC and pEBS7- $\beta$-Ga and $48 \mathrm{~h}$ later left untreated (control) or stimulated for $4 \mathrm{~h}$ with $1 \mathrm{ng} / \mathrm{ml}$ of TNF or $\mathrm{IL}-1 \beta$. NF- $\kappa \mathrm{B}$ activity is expressed as arbitrary units (AU) of luciferase activity relative to $\beta$-galactosidase activity (measure of transfection efficiency). The values represent means of a duplicate experiment. Experiment was repeated twice with essentially same results 
shown in Figure 3, A20-S565R could be constitutively expressed in high levels in MCF-7S1 cells. In addition to the full length $80 \mathrm{kDa}$ A20 protein, transfected cells expressing this mutant of A20 protein contained high levels of an approximately $45 \mathrm{kDa} \mathrm{N}$-terminal cleavage product of $\mathrm{A} 20$ absent in cells expressing the wtA20. This finding suggests that the binding of $\mathrm{A} 20$ to 14-3-3 may protect it from proteolysis. Treatment of MCF-A20-S565R cells for $24 \mathrm{~h}$ with pan-caspase and cathepsin inhibitor z-VAD-fmk (100 mM), caspase-3-inhibitor DEVD-aldehyde $(100 \mu \mathrm{M})$,

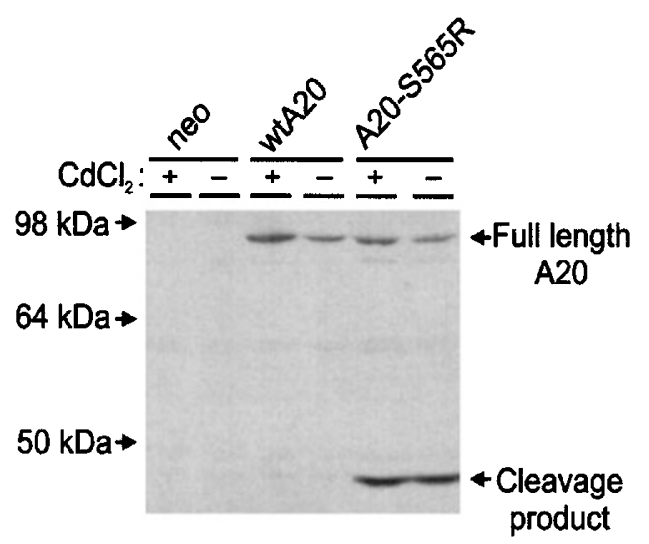

Figure 3 Western blot analysis of levels of wild type A20 and A20-S565R in pooled populations of transfected cells. MCF-7S1 cells were transfected with empty pZEM-neo vector (neo) or pZEM-neo encoding for wild type A20 (wtA20) or A20 mutated in the 14-3-3 binding site (A20-S565R). Cells were left untreated $(-)$ or treated $(+)$ with $10 \mu \mathrm{M} \mathrm{CdCl}_{2}$ for $6 \mathrm{~h}$ before preparations of lysates. Proteins from approximately $7.5 \times 10^{5}$ cells were analyzed using antiFLAG antibody and ECL Western blot analysis system cysteine cathepsin, calpain and proteosome inhibitor ALLN $(100 \mu \mathrm{M})$, or cathepsin B inhibitor CA-074-Me $(10 \mu \mathrm{M})$ had no effect on the cleavage of A20-S565R indicating that it is not a substrate for apoptosis-associated cysteine proteases or proteosome (data not shown). By comparing the effect of A20-S565R to that of the wtA20 we then showed that they were almost equally effective in inhibiting TNF-induced cell death and activation of JNK (Figure 4A,B). Furthermore, as shown earlier by transient transfection experiments in HEK293T cells, also the constitutive expression of A20S565R in MCF-7S1 cells was as effective as that of wild type A20 in inhibiting TNF-induced activation of NF- $\kappa$ B (Figure $4 C$ ). Similar effects on all three TNF responses as well on the stability of the protein were seen in MCF-7S1 cells overexpressing an A20 mutant in which the RSKS sequence in the 14-3-3 binding site of A20 was deleted instead of mutated (data not shown).

\section{A20-mediated inhibition of apoptosis is associated with inhibition of caspase-8 processing}

To investigate at which step of the apoptotic signaling cascade A20 functions, we studied its effect on the processing of caspase- 8 by Western blot analysis. As shown in Figure 5, MCF-neo and MCF-wtA20 cells expressed similar levels of the two isoforms of caspase-8, caspase-8a (p55) and caspase-8b (p53). ${ }^{35}$ In MCF-neo-1 but not in MCF-wtA20-4 cells, treatment with $50 \mathrm{ng} / \mathrm{ml}$ of TNF for $12 \mathrm{~h}$ induced the processing of caspase- 8 resulting in the appearance of $p 41 /$ 43 intermediate cleavage products and a fainter $18 \mathrm{kDa}$ fragment representing the large active subunit of caspase- 8 (Figure 5A). In concordance with our earlier data showing that A20 does not inhibit apoptosis induced by anti-Fas (anti-APO-
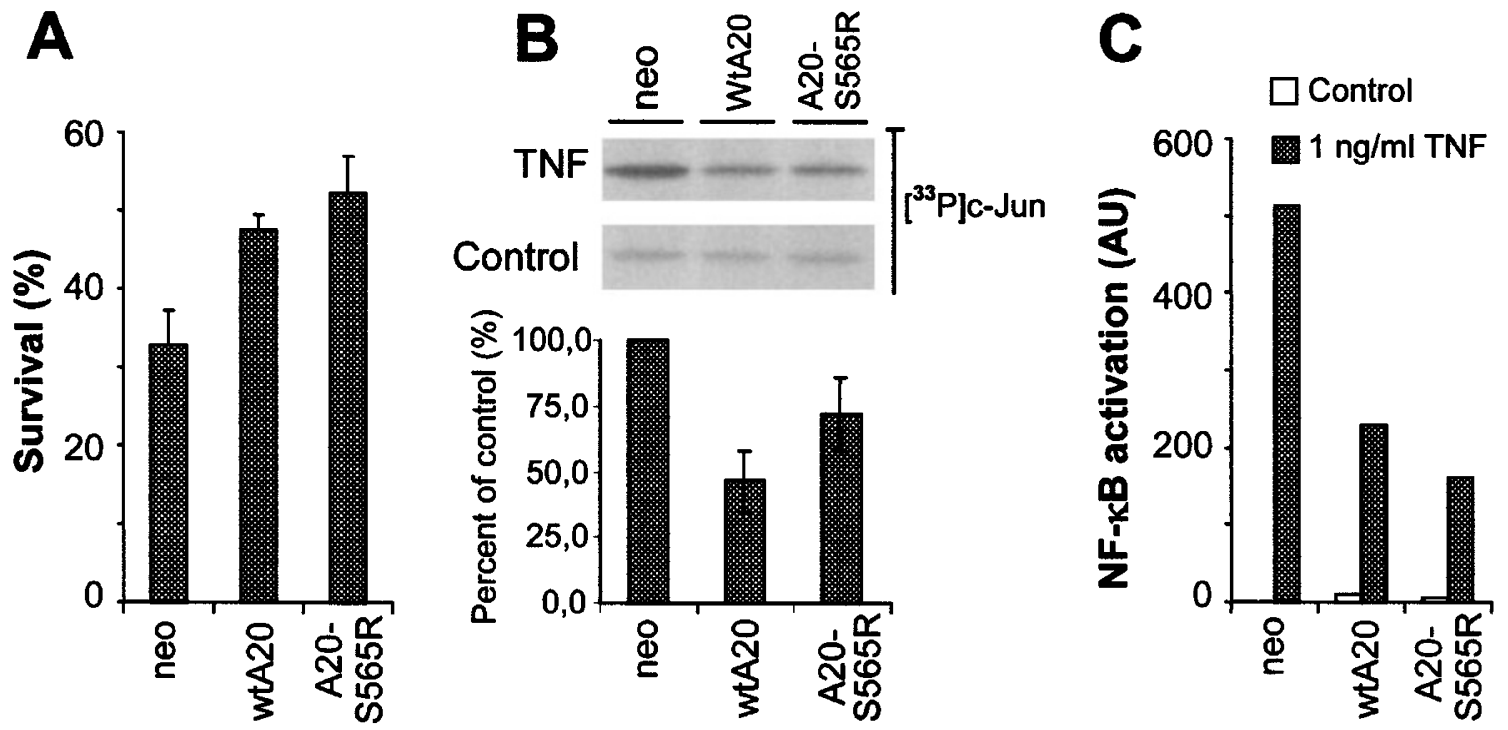

Figure 4 Binding of 14-3-3 proteins is not necessary for A20-mediated inhibition of TNF signaling leading to cell death (A), activation of JNK (B) or activation of $\mathrm{NF}-\kappa \mathrm{B}(\mathbf{C})$. Cell death, JNK activation and NF- $\kappa \mathrm{B}$ activation were analyzed as explained in the legend for Figure 2 . (B) Combined data from three independent experiments is calculated by comparing TNF-induced induction in JNK activity in cells expressing wtA20 or A20-S565R with that of controls cells (=100\%) and is presented as percentage of control \pm S.D. All experiments were performed at least three times with essentially same results. $P<0.05$ in all assays when wtA20 or A20-S565R was compared with neo 
1), ${ }^{22}$ also caspase-8 processing induced by anti-Fas was unaffected by $\mathrm{A} 20$ overexpression (Figure $5 \mathrm{~A}$ ). Furthermore, TNF-induced processing was partially inhibited in MCF-7S1 cell pool transfected with $A 20-C$, but not in the pool expressing A20-N (Figure 5B). TNF-induced processing of caspase-8 preceded the activation of effector caspases by over $6 \mathrm{~h}$ (data not shown). These data indicate that A20 inhibits TNF-induced death signaling already at the level of the activation of caspase-8.

\section{A20 expression does not affect the expression of TRADD, RIP, TRAF2, c-IAP1 or FADD}

We have earlier reported that overexpression of A20 does not have any effect on the cell surface expression of TNF-R $1 .^{22}$ Together with the results presented above this suggests that A20 functions downstream of the TNF-R1 but upstream of processing of caspase-8 and activation of JNK. Therefore, we investigated the possibility that $\mathrm{A} 20$ expression interferes with the expression of TRADD or RIP, TNF-R1-associated adapter proteins implicated in TNF-induced apoptosis as well as in activation of both $\mathrm{JNK}$ and NF- $\kappa \mathrm{B}$. A20 overexpression had, however, no effect on the expression levels of either TRADD
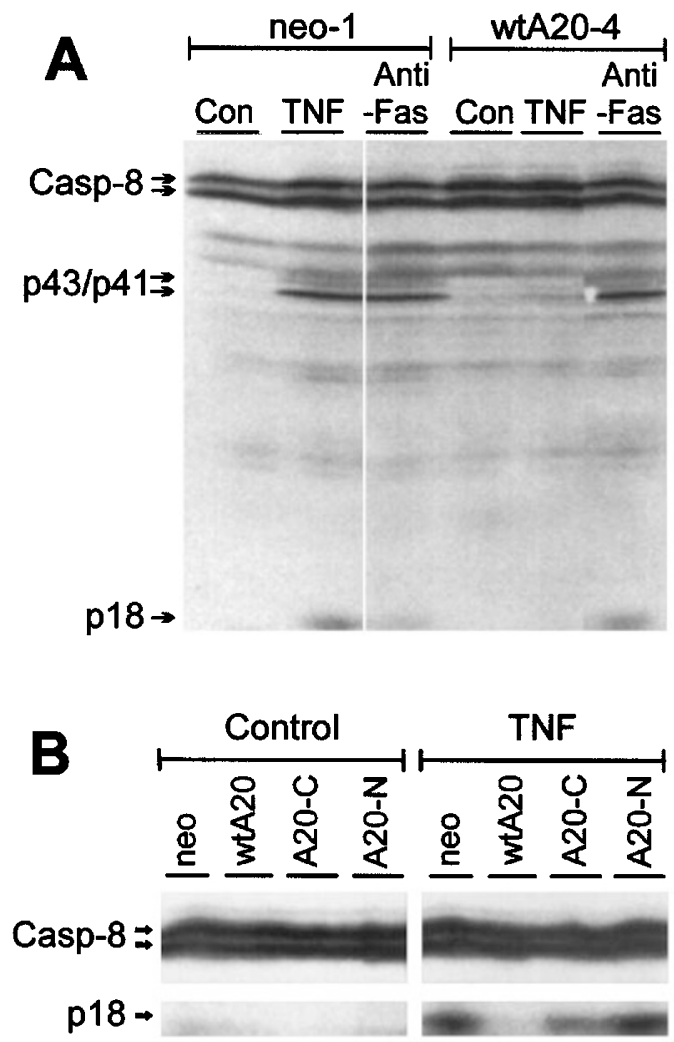

Figure 5 A20 inhibits TNF but not anti-Fas-mediated caspase-8 processing. Lysates from approximately $1 \times 10^{6}$ MCF-7S 1 cells transfected as indicated were left untreated (Con) or treated for $12 \mathrm{~h}$ with $50 \mathrm{ng} / \mathrm{ml}$ TNF or $100 \mathrm{ng} / \mathrm{ml}$ anti-Fas and subjected to $12 \%$ SDS-PAGE and immunoblot analysis with anti-caspase- 8 antibody (C15). The p55 and p53 bands corresponding to the two full-length pro-caspase-8 isoforms (casp-8), the p43/41 bands corresponding to the intermediate cleavage products and the $\mathrm{p} 18$ band corresponding to the active subunit are indicated or RIP. Also expression levels of other receptor-associated proteins including TRAF2, FADD and C-IAP1 remained unaffected by A20 expression (Figure 6).

\section{Discussion}

A20 is a zinc finger protein capable of inhibiting TNF-induced signaling cascades leading to apoptosis as well as to activation of both $\mathrm{AP}-1$ and $\mathrm{NF}-\kappa \mathrm{B}$ transcription factors. ${ }^{22}$ The preferential expression of A20 in poorly differentiated carcinomas suggest that its anti-apoptotic function may play a role in the tumor pathogenesis. ${ }^{27}$ Furthermore, due to its dual role as an anti-apoptotic and anti-inflammatory protein it may have therapeutic potential e.g. in tissue transplantation and diabetes mellitus. ${ }^{25}$ This study was undertaken to gain insight into the poorly understood mechanism of action of A20. The ability of A20 to inhibit all three TNF-induced signaling pathways diverging at the level of TRADD together with its inability to inhibit signaling from Fas suggests that it may function upstream of or at the level of TRADD. ${ }^{22}$ Data presented above show that A20-mediated inhibition of TNFinduced apoptosis is associated with the inhibition of caspase-8 activation. Even though the processing of caspase- 8 was observed first as late as $8-12 \mathrm{~h}$ after the addition of TNF, it clearly preceded the activation of effector caspases as analyzed by cleavage of poly(ADP)ribose polymerase. Furthermore, $\mathrm{Bcl}-\mathrm{X}_{\mathrm{L}}$ has been shown to inhibit TNF-induced caspase-7 processing in MCF-7 cells without affecting that of caspase-8 indicating that caspase-8 activation is an upstream event in our model system. ${ }^{36}$ Thus, the ability of A20 to inhibit TNF-induced caspase-8 processing supports the hypothesis that $A 20$, indeed, functions at the receptor-signaling complex. Also the A20mediated inhibition of TNF-induced activation of AP-1 occurred early in the signaling cascade as the rapid TNFinduced activation of JNK was blocked by A20. Thus, it is interesting to note that $A 20$ is, indeed, recruited to the TNF-R complex upon receptor activation. ${ }^{37}$ It has recently been demonstrated by transient co-transfection experiments that in addition to inhibiting NF- $\kappa \mathrm{B}$ activation induced by TNF receptor triggering or TRADD overexpression, A20 also inhibits that induced by overexpression of RIP or TRAF2. ${ }^{38}$ These results suggest that $A 20$ does not function at the level of TRADD but rather downstream of it, possibly at the level of TRAF2 or RIP. One should, however, be cautious in

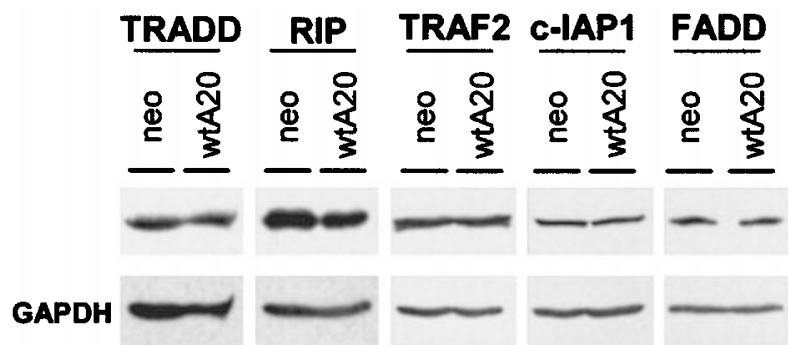

Figure 6 A20 has no effect on the expression levels of TNF-R1-associated proteins. Proteins from approximately $7.5 \times 10^{5} \mathrm{MCF}-$ neo or MCF-wtA20 cells were analyzed by Western blot using indicated antibodies. Experiment was repeated once with essentially same results 
interpreting these results because overexpression of TRAF2 or RIP does not necessarily reflect the situation following stimulation with TNF. The A20-mediated inhibition of TNFinduced processing of caspase- 8 does not fit to the model in which A20 functions downstream of TRAF2 and RIP. Thus, A20 may inhibit the individual signaling pathways by distinct mechanisms. Recent results showing that A20-mediated inhibition of NF- $\kappa \mathrm{B}$ activation occurs in numerous cell lines, whereas its inhibitory effect on apoptosis is limited to highly TNF sensitive cell lines like MCF-7S1, WEHI-S and NIH3T3 supports this idea. ${ }^{22,39,40}$ Furthermore, A20-associated inhibition of NF- $\kappa \mathrm{B}$ activation and apoptosis, has been suggested to be mediated by two distinct downstream effector molecules, ABIN and TXBP151. ${ }^{38,40}$ Another possibility is that $A 20$ regulates a common signaling pathway required for the TNF-induction activation of JNK, NF- $\kappa$ B and caspase-8. To test the latter possibility, we studied the effect of A20 on expression levels of TRADD and RIP, both of which are capable of activating all three TNF-induced signaling pathways. No differences on their expression levels were, however, detected in A20 expressing cells as compared with control cells. Furthermore, A20 overexpression did not alter cellular levels of TRAF-2, FADD or C-IAP1.

A20-mediated inhibition of TNF-induced activation of $\mathrm{NF}-\kappa \mathrm{B}$ has been shown to be independent of the $\mathrm{N}$ terminal TRAF-binding domain. ${ }^{24}$ Later, it has, however, been demonstrated that TRAF2 is not required for TNFinduced NF- $\kappa$ B activation but is needed for that of $\mathrm{JNK}^{8}$ suggesting that binding of A20 to TRAF2 could account for the A20-mediated inhibition of JNK activation instead. Our results show, however, that the zinc finger domain of A20 lacking the TRAF-binding domain was as effective as the wild type $\mathrm{A} 20$ in inhibiting not only NF- $\kappa \mathrm{B}$ activation but also JNK activation and apoptosis. Thus, the functional significance of the binding of $A 20$ to TRAF2 remains questionable and, in fact, the recent data has suggested that A20 may be recruited to the TNF-R1 via RIP and NEMO. ${ }^{37}$ We also show that the binding of A20 to 14-3-3 chaperone proteins is not required for A20-mediated inhibitory effects on any of the three TNF-induced signaling pathways studied. Thus, our mutational analysis of A20 failed to demonstrate any differences on the domains required for the various inhibitory effects of A20. This data indicate that even if the various A20-regulated signaling pathways were inhibited by different mechanisms, the zinc finger domain of the protein is essential for all of them, whereas binding to TRAF2 of 14-3-3 proteins is dispensable.

\section{Materials and Methods}

\section{Construction of expression plasmids}

pZEM-A20 contains the entire open reading frame of A20 downstream from metallothionine promoter in pZEM-neo. ${ }^{22}$ The various deletion mutants of A20 were created by first subcloning the $2.4 \mathrm{~kb}$ Xhol fragment of pZEM-A20 containing A20 into the respective cloning site of pBSII (Stratagene, La Jolla, CA, USA). A deletion of an $\mathrm{N}$-terminal fragment corresponding to amino acids 7-381 was created by digestion with $E c o N l$ and $X m n l$, a deletion of a central fragment corresponding to amino acids $276-518$ by digestion with $\mathrm{Hpal}$ and Smal and a deletion of Cterminal amino acids $516-767$ by digestion with BamH and $B c / l$. Following filling of overhangs with Klenow when necessary, the cDNAs were subcloned into pZEM-neo to create the following plasmids: pZEMA20-C lacking the N-terminal regulatory domain, pZEM-A20- $\triangle$ M lacking the middle part including the first two zinc fingers and pZEM-A20-N lacking most of the five $\mathrm{C}$-terminal zinc fingers.

Mutagenesis of the 14-3-3 binding site in the zinc finger domain of A20 was performed by first subcloning a 598 bp Smal fragment of A20 containing the 14-3-3 binding site into pBSII. The 14-3-3 binding site of $\mathrm{A} 2 \mathrm{O}^{34}$ was destroyed by an amino acid substitution of serine ${ }^{565}$ to arginine (A20-S565R) or a deletion of amino acids 562-567 (A20$\triangle$ RSKS). The mutation primers were synthesized by DNA Technologies (Aarhus, Denmark) and the mutagenesis was performed with 'Quick Change' mutagenesis kit (Stratagene) according to manufacturers instructions. Mutations were confirmed by sequencing (Amersham Life Science Sequenase $2.0 \mathrm{Kit}$ ) and the correctly mutated fragments were then subcloned into the Smal site of pBSIIA20 and further subcloned into Xhol site of pZEM-neo, creating pZEMA20-S565R and pZEM-A20- $\triangle 14-3-3 B S$.

\section{Cell culture and treatments}

MCF-7S1 cell line is a subclone of MCF-7 selected for its high sensitivity to recombinant TNF- $\alpha{ }^{41}$ Cells were cultured at $37^{\circ} \mathrm{C}$ in humidified air atmosphere with $5 \% \mathrm{CO}_{2}$. RPMl (Life Technologies, Prailey, UK) supplemented with $10 \%$ heat-inactivated fetal calf serum (Biological Industries, Beit Haemek, Israel), penicillin and streptomycin was used as growth medium for all cell lines and is referred to as complete medium (CM). Media used for stably transfected cell lines was further supplemented with $0.4 \mathrm{mg} / \mathrm{ml} \mathrm{G} 418$ (Calbiochem, La Jolla, CA, USA).

Recombinant human TNF- $\alpha$ was provided by Dr. Anthony Cerami (Kenneth Warren Laboratories, Tarrytown, NY, USA) and the monoclonal anti-Fas antibody (anti-APO-1) by Dr. PH Krammer (German Cancer Research Center, Heidelberg, Germany). IL-1 $\beta$ with specific activity of $1.4 \times 10^{4} \mathrm{U} / \mathrm{ml}$ was purchased from Genzyme (Cambridge, MA, USA), z-Val-Ala-DL-Asp- $\mathrm{CH}_{2} \mathrm{~F}$ (zVAD-fmk) from Bachem (Bubendorf, Switzerland), N-Acetyl-Leu-Leu-Nle-CHO (ALLN) from Calbiochem-Novabiochem Co. (La Jolla, CA, USA), CA-074-Me from Peptide International (Louisville, KY, USA), z-PheAla- $\mathrm{CH}_{2} \mathrm{~F}$ (zFA-fmk) from Enzyme System Products (Livermore, CA, USA), and acetyl-Asp-Glu-Val-Asp-aldehyde (DEVD-CHO) from Biomol (Plymouth Meeting, PA, USA).

\section{Survival assay}

Cells were seeded out on a 96-well plate (3500 cells/well) and grown for $18 \mathrm{~h}$. When indicated, A20 expression was induced by incubating cells with $10 \mu \mathrm{M} \mathrm{CdCl}_{2}$ for $6 \mathrm{~h}$ before the addition of indicated concentrations of TNF. The dimethylthiazol-diphenyltetrazolium salt (MTT) assay was used to measure the cell viability essentially as described previously. ${ }^{41}$

\section{Transfections}

Transfection of MCF-7S1 cells were performed by electroporation (960 $\mu \mathrm{FD}, 240 \mathrm{~V}$; BioRad Gene Pulser) employing $5-7 \times 10^{6}$ cells in $250 \mu \mathrm{l} \mathrm{CM}, 10 \mu \mathrm{g}$ plasmid DNA, and $5 \mu \mathrm{l}$ carrier DNA. After transfection cells were incubated for $5-10 \mathrm{~min}$ at $25^{\circ} \mathrm{C}$ washed once in $\mathrm{CM}$ and seeded in tissue culture flasks to create pooled population 
or in cloning plates to obtain single cell clones. After 2 days in culture, $400 \mu \mathrm{g} / \mathrm{ml}$ of G418 was added to the medium. Experiments with pooled populations of transfectants were performed with cells that had been in culture for 2-4 weeks after the transfection.

\section{Activation of JNK pathway}

Lysates from cells treated as indicated were precleaned by incubation with $100 \mu \mathrm{l}$ Pansorbin cells (Calbiochem) for $20 \mathrm{~min}$ at $4^{\circ} \mathrm{C}$ and the activation of JNK was analyzed by a solid-phase kinase assay essentially as described previously. . $^{2,43}$

\section{Transient transfection and luciferase assay}

The activation of NF- $\kappa \mathrm{B}$-like transcription factors was analyzed as described previously employing a NF- $k \mathrm{~B}$-driven reporter plasmid, p3K-INF-LUC, which contains three copies of a consensus NF- $\kappa$ B binding sequence in front of human minimal interferon promoter and Photinius pyralis luciferase coding sequence. ${ }^{22}$ Transient transfections were performed by DEAE dextran method using $5 \mu \mathrm{g}$ of p3K-INF-LUC and $3 \mu \mathrm{g}$ of pEBS- $\beta$-Gal per $10^{6}$ cells. $^{22}$ Two days after the transfection, cells were left untreated or treated with the indicated concentrations of TNF or IL-1 $\beta$ for $4 \mathrm{~h}$ prior to harvesting. Luciferase activity in the lysates was measured with the Promega Luciferasse assay system and the transfection efficiency was analyzed by $\beta$-galactosidase assay using o-nitrophenyl- $\beta$-Dgalactopyranoside (ONPG; Sigma Chemical Co.) as a chromogenic substrate. The values from the luciferase assay were corrected according to the transfection efficiency.

\section{Immunoblot analysis}

One million cells/well were plated in a 6-well-plate in $4 \mathrm{ml} \mathrm{CM}$ and grown for $24 \mathrm{~h}$ of which the last $6 \mathrm{~h}$ were with or without $10 \mu \mathrm{M} \mathrm{CdCl}$. Cells were harvested by scraping, washed three times with cold PBS, lysed in Laemmli Sample Buffer containing $5 \% \beta$-Mercaptoethanol (approximately $2 \times 10^{6}$ cells $/ 150 \mu \mathrm{l}$ ), boiled for $5 \mathrm{~min}$ and sonicated (duty cycle $40 \%$, output 4; Branson Sonifier). Proteins from approximately $7.5 \times 10^{5}$ cells/lane were resolved in a SDS-polyacrylamide gel and transferred to Hybond ECL filter (Amersham International, UK). The filters were incubated for $30 \mathrm{~min}$ at $25^{\circ} \mathrm{C}$ in blocking buffer containing $5 \%$ dry milk in Tris-Buffered Saline (TBS) and $0.1 \%$ tween (Merck). After two washes in TBS+0.1\% tween, filters were incubated for $18 \mathrm{~h}$ at $4{ }^{\circ} \mathrm{C}$ with anti-FLAG $(1: 1000$; KODAK or SIGMA Chemical Co.), anti-GAPDH $(0.4 \mu \mathrm{g} / \mathrm{ml}$; Biogenesis, Poole, UK), anti-TRADD, anti-RIP, anti-TRAF2, anti-c-IAP1 or anti-FADD antibodies $(2.5 \mu \mathrm{g} /$ $\mathrm{ml}$; Santa Cruz Biotechnology Inc., Santa Cruz, CA, USA) in TBS $+0.1 \%$ tween. The filters were then washed $5 \times 5 \mathrm{~min}$ TBS $+0.1 \%$ tween and incubated in a 1:1000-1:40 000 dilution of the peroxidase-conjugated anti-mouse IgG (Dako A/S, Denmark) at $25^{\circ} \mathrm{C}$ for $30 \mathrm{~min}$ and thereafter washed $6 \times 5 \mathrm{~min}$. To detect caspase-8, C15 anti-caspase-8 antibody (kindly provided by Dr. Peter Krammer, Heidelberg, Germany) was used as described previously. ${ }^{35}$ Finally, ECL Western blotting reagents (Amersham) were added and the filters were exposed to ECL Hyperfilm (Amersham) and developed.

\section{Statistical analysis}

The statistical significance of the results was assessed by the students $t$-test.

\section{Acknowledgements}

We wish to thank Dr. Peter Krammer for anti-Apo-1 and anti-caspase-8 antibodies, Dr. Anthony Cerami for TNF and Birgit Poulsen for technical assistance. This work was supported by the Danish Cancer Society and the Danish Medical Research Council.

\section{References}

1. Ashkenazi A and Dixit VM (1999) Apoptosis control by death and decoy receptors. Curr. Opin. Cell. Biol. 11:255-260

2. Jäättelä M (1991) Biological activities and mechanisms of action of tumor necrosis factor alpha/cachectin. Lab. Invest. 64: 724-742

3. Wallach D, Varfolomeev EE, Malinin NL, Goltsev YV, Kovalenko AV and Boldin MP (1999) Tumor necrosis factor receptor and Fas signaling mechanisms. Annu. Rev. Immunol. 17: $331-367$

4. Hsu H, Shu H-B, Pan M-G and Goeddel DV (1996) TRADD-TRAF2 and TRADDFADD interactions define two distinct TNF receptor 1 signal transduction pathways. Cell 84: 299-308

5. Hsu H, Huang J, Shu HB, Baichwal V and Goeddel DV (1996) TNF-dependent recruitment of the protein kinase RIP to the TNF receptor-1 signaling complex. Immunity 4: 387-396

6. Boldin MP, Goncharov TM, Goltsev YV and Wallach D (1996) Involvement of $\mathrm{MACH}$, a novel MORT1/FADD-interacting protease, in Fas/APO-1- and TNF receptor-induced cell death. Cell 85: 803-815

7. Muzio M, Chinnaiyan AM, Kischkel FC, O'Rourke K, Shevchenko A, Ni J, Scaffidi C, Bretz JD, Zhang M, Gentz R, Mann M, Krammer PH, Peter ME and Dixit VM (1996) FLICE, a novel FADD-homologous ICE/CED-3-like protease, is recruited to CD95 (Fas/APO-1) death-inducing signaling complex. Cell 85: 817-827

8. Lee SY, Reichlin A, Santana A, Sokol KA, Nussenzweig MC and Choi Y (1997) TRAF2 is essential for JNK but not NF- $\kappa$ B activation and regulates lymphocyte proliferation and survival. Immunity 7: 703-713

9. Kelliher MA, Grimm S, Ishida Y, Kuo F, Stanger BZ and Leder P (1998) The death domain kinase RIP mediates the TNF-induced NF-kappaB signal. Immunity 8: 297-303

10. Xia Z, Dickens M, Reingeaud J, Davis RJ and Greenberg ME (1995) Opposing effects of ERK and JNK-p38 MAP kinases on apoptosis. Science 270: 13261331

11. Verheij M, Bose R, Lin XH, Yao B, Jarvis WD, Grant S, Birrer MJ, Szabo E, Zon LI, Kyriakis JM, Haimovitz-Friedman A, Fuks Z and Kolesnick RN (1996) Requirement for ceramide-initiated SAPK/JNK signalling in stress-induced apoptosis. Nature 380: 75-79

12. Liu Z-G, Hsu H, Goeddel DV and Karin M (1996) Dissection of TNF receptor 1 effector functions: JNK activation is not linked to apoptosis while NF-kB activation prevents cell death. Cell 87: 565-576

13. Natoli G, Costanzo A, Lanni A, Templeton DJ, Woodgett JR, Balsano C and Levrero M (1997) Activation of SAPK/JNK by TNF receptor through a noncytotoxic TRAF2-dependent pathway. Science 275: 200-203

14. Kuan CY, Yang DD, Samanta Roy DR, Davis RJ, Rakic P and Flavell RA (1999) The Jnk1 and Jnk2 protein kinases are required for regional specific apoptosis during early brain development. Neuron 22: 667-676

15. Barnes PJ and Karin M (1997) Nuclear factor-kappaB: a pivotal transcription factor in chronic inflammatory diseases. N. Engl. J. Med. 336: 1066-1071

16. Beg AA and Baltimore D (1996) An essential role for NF- $\kappa B$ in preventing TNF- $\alpha$ induced cell death. Science 274: $782-784$

17. Wang C-Y, Mayo MW and Baldwin Jr AS (1996) TNF- and cancer therapyinduced apoptosis potentiation by inhibition of NF- $k$ B. Science 274: 784-787

18. Antwerp DJ, Martin SJ, Kafri T, Green DR and Verma IM (1996) Suppression of TNF- $\alpha$-induced apoptosis by NF- $\kappa$ B. Science $274: 787-789$

19. Dixit VM, Green S, Sarma V and Prochownik EV (1990) Tumor necrosis factor- $\alpha$. induction of novel genes in human endothelial cells including a macrophage specific chemotaxin. J. Biol. Chem. 265: 2973-2978

20. Opipari AW, Boguski MS and Dixit VM (1990) The A20 cDNA induced by tumor necrosis factor- $\alpha$ encodes a novel type of zinc finger protein. J. Biol. Chem. 265: $14705-14708$

21. Opipari AW, HuHM, Yabkowitz Rand Dixit VM (1992)The A20 zinc-finger protein protects cells from TNF cytotoxicity. J. Biol. Chem. 267: 12424-12427 
22. Jäättelä $M$, Mourizen $H$, Elling $F$ and Bastholm L (1996) A20 zinc finger protein inhibits TNF and IL-1 signaling. J. Immunol. 156: 1166-1173

23. Cooper JT, Stroka DM, Brostjan C, Palmetshofer A, Bach FH and Ferran C (1996) A20 blocks endothelial cell activation through a NF-kB-dependent mechanism. J. Biol. Chem. 271: 18068-18073

24. Song HY, Rothe M and Goeddel DV (1996) The tumor necrosis factor-inducible zinc finger protein A20 interacts with TRAF1/TRAF2 and inhibits NF- $k$ B activation. Proc. Natl. Acad. Sci. USA 93: 6721-6725

25. Grey ST, Arvelo MB, Hasenkamp W, Bach FH and Ferran C (1999) A20 inhibits cytokine-induced apoptosis and nuclear factor kappaB- dependent gene activation in islets. J. Exp. Med. 190: 1135-1146

26. Lee EG, Boone DL, Chai S, Libby SL, Chien M, Lodolce JP and Ma A (2000) Failure to regulate TNF-induced NF-kappa B and cell death responses in A20deficient mice [In Process Citation]. Science 289: 2350-2354

27. Codd JD, Salisbury JR, Packham G and Nicholson LJ (1999) A20 RNA expression is associated with undifferentiated nasopharyngeal carcinoma and poorly differentiated head and neck squamous cell carcinoma. J. Pathol. 187: $549-555$

28. Cao CD, Xiong J, Takeuchi M, Kurama T and Goeddel DV (1996) TRAF6 is signal transducer for interleukin-1. Nature 383: $443-446$

29. Heyninck K and Beyaert R (1999) The cytokine-inducible zinc finger protein A2O inhibits IL-1-induced NF-kappaB activation at the level of TRAF6. FEBS Lett. 442: $147-150$

30. Vincenz C and Dixit VM (1996) 14-3-3 proteins associate with A20 in an isoformspecific manner and function both as chaperone and adapter molecules. J. Biol. Chem. 271: 20029-20034

31. Gajewski TF and Thompson CB (1996) Apoptosis meets signal transduction: elimination of a BAD influence. Cell 87: 589-592

32. Zha J, Harada H, Yang E, Jockel J and Korsmeyer SJ (1996) Serine phosphorylation of death agonist $B A D$ in response to survival factor results in binding to 14-3-3 not BCL-X $\mathrm{X}_{\mathrm{L}}$. Cell 87: 619-628

33. Brunet A, Bonni A, Zigmond MJ, Lin MZ, Juo P, Hu LS, Anderson MJ, Arden KC Blenis J and Greenberg ME (1999) Akt promotes cell survival by phosphorylating and inhibiting a Forkhead transcription factor. Cell 96: 857-868
34. De Valck D, Heyninck K, Van Criekinge W, Vandenabeele P, Fiers W and Beyaert R (1997) A20 inhibits NF-kB activation independently of binding to 14-33 proteins. Biochem. Biophys. Res. Comm. 238: 590-594

35. Scaffidi C, Medema JP, Krammer PH and Peter ME (1997) FLICE is predominantly expressed as two functionally active isoforms, caspase-8/a and caspase-8/b. J. Biol. Chem. 272: 26953-26958

36. Srinivasan A, Li F, Wong A, Kodandapani L, SmidtJrR, Krebs JF, Fritz LC, WuJC and Thomaselli KJ (1998) Bcl-xL functions downstream of caspase-8 to inhibit Fas- and tumor necrosis factor receptor 1-induced apoptosis of MCF7 breast carcinoma cells. J. Biol. Chem. 273: 4523-4529

37. Zhang SQ, Kovalenko A, Cantarella G and Wallach D (2000) Recruitment of the IKK signalosome to the p55 TNF receptor: RIP and A20 bind to NEMO (IKKgamma) upon receptor stimulation. Immunity 12: $301-311$

38. Heyninck K, De Valck D, Berghe WV, Van Criekinge W, Contreras R, Fiers W, Haegeman G and Beyaert R (1999) The zinc finger protein A20 inhibits TNFinduced NF-kappaB-dependent gene expression by interfering with an RIP-or TRAF2-mediated transactivation signal and directly binds to a novel NF-kappaBinhibiting protein ABIN. J. Cell. Biol. 145: 1471-1482

39. Wissing D, Mouritzen $H$ and Jäättelä M (1998) TNF-induced mitochondrial changes and activation of apoptotic proteases are inhibited by A20. Free Radical Biol. Med. 25: 57-65

40. De ValckD, Jin DY, HeyninckK, Van de Craen M, Contreras R, Fiers W, Jeang KT and Beyaert R (1999) The zinc finger protein A20 interacts with a novel antiapoptotic protein which is cleaved by specific caspases [In Process Citation]. Oncogene 18: 4182-4190

41. Jäättelä M, Benedict M, Tewari M, Shayman JA and Dixit VM (1995) Bcl-x and $\mathrm{Bcl}-2$ inhibit TNF and Fas-induced apoptosis and activation of phospholipase $\mathrm{A}_{2}$ in breast carcinoma cells. Oncogene 10: 2297-2305

42. Kallunki T, Su B, Tsigelny I, Sluss HK, Derijard B, Moore G, Davis R and Karin M (1994) JNK2 contains a specificity-determining region responsible for efficientcJun binding and phosphorylation. Genes Dev. 8: 2996-3007

43. Jäättelä M, Wissing D, Kokholm K, Kallunki T and Egeblad M (1998) Hsp70 exerts its anti-apoptotic function downstream of caspase-3-like proteases. EMBO J. 17: 6124-6134 